\title{
Socio-Economic Factors Influencing on Total Fertility Rate in Iran: A Panel Data Analysis for the Period of 2002-2012
}

Hasan Jafari ${ }^{1}$, Ebrahim Jaafaripooyan ${ }^{2}$, Abou Ali Vedadhir ${ }^{3}$, Abbas Rahimi Foroushani ${ }^{4}$, Bahman Ahadinejad ${ }^{5}$, Abolghasem Pourreza ${ }^{6}$

${ }^{1}$ Ph.D. Student in Health Policy, Department of Management \& Health Economic, School of Public Health, Tehran University of Medical Science, Tehran, Iran

${ }^{2}$ Assistant Professor, Department of Management \& Health Economic, School of Public Health, Tehran University of Medical Science, Tehran, Iran

${ }^{3}$ Associate Professor, Department of Anthropology, University of Tehran, Tehran, Iran

${ }^{4}$ Professor, Department of Epidemiology and Biostatistics, School of Public Health, Tehran University of Medical Science, Tehran, Iran

${ }^{5}$ Ph.D. Student in Health Economics, Department of Management \& Health Economic, School of Public Health, Tehran University of Medical Science, Tehran, Iran

${ }^{6}$ Professor, Department of Management \& Health Economic, School of Public Health, Tehran University of Medical Science, Tehran, Iran

\section{Type of article: Original}

\begin{abstract}
Introduction: Over the last few decades, total fertility rate (TFR) has followed a downward trend in Iran. The consequences of this trend from the perspectives of some are negative. Considering the macro-population policies in recent years, this study aimed to examine the effect of some macro socio-economic variables, including divorce, marriage, urbanization, and unemployment rate on TFR in Iran from 2002 to 2012.

Methods: This time series research was conducted in 2015 using the databases of the National Organization for Civil Registration (NOCR) and the Statistical Center of Iran. The study population was the related data of provinces in the selected variables. The main methods used in the research were the common unit root test, Pedroni Cointegration test, redundant fixed effects tests, correlated random effects-Hausman test, and panel least squares of fixed effects. In order to determine the suitable model for estimating panel data, likelihood ratio and Huasman tests were done using Eviews software, and the fixed effects regression model was chosen as the dominant model.

Results: The results indicated that the divorce rate had a negative and significant effect on TFR $(\mathrm{p}<0.05)$. A positive and significant relationship between marriage rate and TFR variables also was observed $(p<0.05)$. Urbanization rate $(\mathrm{p}=0.24)$ and unemployment rate $(\mathrm{p}=0.36)$ had no significant relationship with TFR. According to F statistic, significance of the overall model also was confirmed $(p<0.001)$.

Conclusion: Due to the lower effect of the studied factors on the reduction of TFR, it seems that variables other than the ones studied, as well as cultural factors and values, might be fundamental factors for this change in the country.
\end{abstract}

Keywords: Total fertility rate, Divorce, Marriage, Urbanization, Unemployment

\section{Introduction}

Population policies in any country are considered as the basis of social-economic development (1). These policies encompass all population trends, morbidity and mortality, reproduction and family formation, distribution,

\section{Corresponding author:}

Professor Dr. Abolghasem Pourreza, Department of Management \& Health Economic, School of Public Health, Tehran University of Medical Science, Tehran, Iran.

Tel: +982188989129, Fax: +982166462267, Email: abolghasemp@yahoo.com

Received: January 25, 2016, Accepted: April 21, 2016, Published: June 2016

iThenticate screening: April 15, 2016, English editing: May 17, 2016, Quality control: June 02, 2016

(C) 2016 The Authors. This is an open access article under the terms of the Creative Commons Attribution-NonCommercialNoDerivs License, which permits use and distribution in any medium, provided the original work is properly cited, the use is non-commercial and no modifications or adaptations are made. 
migration, and, overall, the size and structure of the population of a country (2). Of them, fertility is a principal component of population dynamics that total fertility rate (TFR) is a common indicator for it (3). TFR is the average number of live births a woman would have throughout her life. In the case of TFR $<2.1$, a decline in the population of countries could occur (4). TFR has experienced many changes in recent years. The United Nations Population Division has long-term forecasts for it that demonstrates continued fertility declines in the developing world (5). Shapiro and Gebreselassie remark that most countries in sub-Saharan Africa are still facing fertility declines. They showed in the other regions of the world, every country-with the exception of Armenia and Indonesia-also is experiencing decreasing fertility. These regions contain both countries that have a modest decline, such as Guatemala and India, and those for which the decline is more substantial, for instance Morocco, Brazil, and Yemen (6). As a developing country, Iran has a TFR $=1.75$ births per woman according to the last census of 2011, which has decreased from the rate of 1.84 in 2006 (7). TFR in Iran began to decline in 1985 when it was 6.3 births per woman, and, lately, it has decreased markedly (8). Despite various fertility levels and patterns in different parts of the country, the variation rate has diminished. For example, according to the 2006 census, TFR for urban and rural areas were 1.75 and 2.1, respectively, as compared to 3 and 4.2 in 1994. Moreover, four provinces had TFR values between 1.2 and 1.6 and 13 had rate between 1.7 and 2.1 (9). Consequently, the rate of growth of the older population is increasing and is predicted to reach nearly $24 \%$ by 2050 (10), meaning that the population age structure of the country is converting from youth into aging (11). Various factors are been mentioned in the literature to explain the decline in TFR. For instance, on economic factors, Adsera pointed that unemployment and unstable contracts might reduce fertility significantly by delaying childbearing (12). Also, it pointed to young couples who significantly postpone their childbearing due to uncertain conditions in the labor market, such as temporary employment contracts or job instability (13). Caldwell (1982) asserted that the rising costs of children (e.g., for education) and their declining economic value (e.g., for labor and old age security) result in a decline in the desired family size. This, in turn, leads to an increase in the demand for and the use of birth control (14). He showed that rising educational levels make childrearing more expensive than it used to be, which could indicate that wealth flows are changing directions from parents to children (15). Also, based on a survey by Kreyenfeld, economic indicators in the form of unemployment and subjective perceptions of the economic situation (e.g., fear of job security) make highly educated women delay bearing their first child (16). In a study by Raziyeh Shakoori in Iran, employment and financial independence of women were the two main causes of divorce and, consequently, the decline in fertility (17). Social factors are other issues that might affect TFR. For example, in rural communities with the traditional agriculture context, due to high mortality, high fertility prevails to ensure the survival of the population. As a society develops and socio-economic shifts occur, such as increasing education and urbanization, the reduction in child mortality, and the increasing cost of children, the actual fertility decreases (18). AbbasiShavazi and Asgari (2005) studied family and fertility changes in Iran and indicated that women have fewer children due to the high degree of urbanization and the increasing marriage age and education levels as modern patterns of fertility (19). In a study in Saudi Arabia, it was shown that marriage patterns have been changed by the increasing ages of people when they get married, reducing early marriages in the country, and by improving women's education and decreasing infant mortality, thus, fertility rates have been decreased (20). Among the indicators of development, there was a significant correlation between degree of urbanization and fertility in Bongaarts's work (21). Hence, understanding the notion of TFR and the factors that affect its decline could present helpful policy insights and implications towards preventing and managing its effects in different societies. Despite all of the above-mentioned studies, overall, there are very few studies on the determinants of fertility decline in the developing countries, especially in Iran taking a qualitative approach. Therefore, this study was conducted using the panel data model. Operationally, we selected four indicators of socioeconomic development, i.e., divorce, marriage, urbanization, and unemployment rates, to examine their effects on TFR in Iran between 2002 and 2012. This could help to form a detailed and comprehensive understanding of population issues and, thereby, aid in the development of sustainable population policies.

\section{Material and Methods}

\subsection{Study design and data colelction}

This study was performed using econometric methods. The panel data method was used to determine the association between divorce, marriage, urbanization, and unemployment rate and TFR in Iran between 2002 and 2012 . Required data on variables was obtained from the NOCR database and the statistical center of Iran. Data on TFR for ten years (2002-2012) were taken from Abbasi-Shavazi and Hosseini-Chavoshi's work (22). At this stage, a checklist was developed based on the needed variables to check when we went to the data centers, and, using this tool, we completed it based on different provinces. It should be noted that a letter of introduction from the faculty was 
prepared for them, and, at the same time, some explanations were provided to them about the topic of the study and its importance to ensure their cooperation.

\subsection{The estimation models}

To determine a suitable model for estimating panel data, likelihood ratio and Huasman tests were done using Eviews 7 software. In the likelihood ratio test, the null hypothesis expresses the absence of a cross-sectional effect. In contrast, a rival hypothesis shows the existence of the fixed effect. In the Huasman test, the null hypothesis also displays the non-correlation between the disturbance term and exogenous variables. The rival hypothesis of the Huasman test indicates that an appropriate model is the random effect regression (23). Correlation among the study variables was shown by capturing this function: $T F R=f(M A R, D I V, U, U R)$; where MAR: Marriage rate, DIV: Divorce rate, UR: Urbanization rate, and U: Unemployment rate. The proper regression model was given by: LTFR $=\beta 0+\beta 1$ LDIVit $+\beta 2$ LMARit $+\beta 3$ LURit $+\beta 4$ LUit + uit

\section{Results}

Table 1 presents the descriptive statistics of the given variables. According to that, the urbanization percentage of our country was high, and the mean of TFR was estimated to be lower than the substitution threshold in the country. Before econometrics estimation, the stationary level of variables should be determined. In the literature on econometrics, regression of a non-stationary variable upon another non-stationary variable might lead to a so-called spurious regression. In this article, Levin, Lin, and Chu's unit root test was run to explain stationary variables (Table 2). The results in Table 2 reflect that all variables were first-order-integrated. In other words, by once differencing, all variables convert to the stable level. An important exception arises when two or more one-order, integrated variables are co-integrated, i.e., if there is a particular linear combination of these non-stationary variables that is stationary. We used the Pedroni test to examine the co-integration of variables. The results of the Pedroni test showed that the variables were co-integrated and that they had long run linkage $(p<0.05)$. Different models were introduced to estimate the panel data. Based on the econometrics literature, three models were specified, i.e., pooled regression, fixed effect regression, and random effect regression models. Proper tests were used to choose the best model. To diagnose between the pooled and fixed effect regression, we used the redundant fixed effects test, which rejected the null hypothesis $(\mathrm{p}<0.05)$. Hence, we could say there is a cross section fixed effect. The next step was to determine the type of effects. For assessing the effect behavior, the Huasman test was employed. Results of estimating the fixed model are shown in Table 3, which indicates that the divorce rate has an adverse effect on TFR. In addition, there was a significant direct relationship between marriage rate and TFR. Furthermore, urbanization rate and unemployment rate did not have significant relationship with TFR.

Table 1. Descriptive results of variables during 2002-2012

\begin{tabular}{|l|l|l|l|}
\hline Variable & Mean & Std. Deviation & Range \\
\hline Total Fertility Rate & 1.96 & 0.45 & 2.84 \\
\hline Marriage Rate & $11.54^{*}$ & 1.87 & 17.03 \\
\hline Divorce Rate & $1.24^{*}$ & 0.51 & 2.44 \\
\hline Urban Rate & 64.17 & 0.75 & 48.73 \\
\hline Unemployment Rate & 11.99 & 3.58 & 31.20 \\
\hline
\end{tabular}

*Per 1000 population

Table 2. Results of common unit root test for variables

\begin{tabular}{|c|c|c|c|c|}
\hline \multirow[t]{2}{*}{ Variables } & \multicolumn{2}{|c|}{ Stationary at Level } & \multicolumn{2}{|c|}{ Stationary at single difference } \\
\hline & Statistic & Prob. & Statistic & Prob. \\
\hline $\begin{array}{l}\text { LTFR } \\
\end{array}$ & 3.67 & 0.41 & 6.15 & 0.001 \\
\hline LMAR & 3.49 & 0.99 & 8.79 & 0.001 \\
\hline LDIV & 1.51 & 0.93 & 6.85 & 0.001 \\
\hline LU & 1.01 & 0.15 & 7.59 & 0.001 \\
\hline LUR & 5.24 & 1.00 & 2.63 & 0.004 \\
\hline
\end{tabular}

LMAR: Marriage rate, LDIV: Divorce rate, LUR: Urbanization rate, LU: Unemployment rate 
Table 3. Results of panel least squares of fixed effects (Dependent variable: LTFR)

\begin{tabular}{|l|l|l|l|}
\hline Variables & Coefficient & t-Statistic & Prob. \\
\hline LDIV & -0.031 & -2.145 & 0.03 \\
\hline LMAR & 0.042 & 1.459 & 0.04 \\
\hline LUR & -0.085 & -1.154 & 0.24 \\
\hline LU & -0.015 & -1.005 & 0.36 \\
\hline C & 1.064 & 3.361 & 0.001 \\
\hline
\end{tabular}

Adjusted $\mathrm{R}^{2}=0.97, \mathrm{~F}$-statistic $=260.54$, Durbain-Watson $=1.89, \mathrm{p}$-value $=0.001$

\section{Discussion}

Based on the results, except the divorce rate and marriage rate, effects of other studied factors on TFR were not confirmed. The results of this study compared to those that have been done in this area presented below. Over the past 25 years, we have witnessed dramatic increases in the number of divorces in the country, so that the crude divorce rate of 0.7 has reached to 1.9 (per 1000 population) over the period of 1986-2011 (24). In our analysis, a significant and adverse relationship was observed between divorce rate and TFR. In other words, a one percent increase in the divorce rate results in a $0.03 \%$ decrease in TFR, on average. With the decrease in the durability of marriages, the chance of childbearing also is diminished. Consequently, many years of potential reproductive opportunity are lost. All of these could have significant effects on TFR; so that, this adverse association was confirmed based on the present study. In a study within the country, employment and financial independence of women were considered as causes of divorce and, thus, fertility decline (17). Lee and Bumpass (2008) concluded that, if a woman's work is irregular and takes long hours of her time, even though her income is very high, it does not help the stability of the family (25). Another variable that we examined in relation to the decrease in TFR was the marriage rate. It had significant relationship with TFR, so that a one percent increase in marriage rate increased TFR by 0.04 percent, on average. Abdul Salam, in his study, showed that marriage patterns have changed by reducing early marriage and improving women's education, marriage age, and reducing infant mortality and children cause to reduce the number of childbirths in Saudi Arabia (20). In this study, the urbanization rate had a negative, but statistically insignificant effect, on TFR. This relationship has been investigated in several studies. Along with the urbanization and industrialization of societies, the cost of raising children has increased and, because of economic considerations, the average number of children born decreases (26). Abbasi-Shavazi and Asgari studied the family changes and fertility decline among 1,249 women aged 15 to 49 in Yazd Province, Iran, and showed urbanization and higher education and higher age of marriage cause people to have fewer children (19), but our results do not support this finding. Bongaarts, using the fixed effects regression for the period of 1960-65 to 199095, expressed that among the development indicators, the GDP per capita and participation of workforce in the agriculture sector did not have a significant relationship with TFR and only urbanization had a significant and inverse relationship (21), but this was contrary to our analysis. Some have posited that fertility reduction in all provinces of Iran, across the rural and urban areas or the convergence of the reduction, has occurred (22) and that a simultaneous and substantial decrease across all geographic regions and in both urban and rural areas had occurred and there is a considerable degree of narrowing of urban-rural and regional (27). Hence, there was no significant relationship between urbanization rate and TFR that are consistent with our results.In this study, unemployment rate and TFR showed a negative but statistically insignificant association. The linkage between women's employment and fertility is mutual. Women's employment contributes to decline in fertility, and women's entering to labor market is affected by fertility. The childbearing age of women has increased because of changes in the socio-cultural conditions, especially employment (28). Addio and Ercole claimed that, statistically, there was a positive significant relationship between enhanced financial security of women through participation in the labor market and a reverse correlation between the women unemployment with fertility $(12,29,30)$. While the relationship between women's employment and fertility rate in 1970s was adverse, but in the 1990s, it became a positive correlation to the extent that countries with high employment levels for women have higher levels of fertility (31). These results are in contrast to studies based on economic model that expresses the fertility of women who are working, because of facing with more opportunity costs of children are in lower fertility levels $(31,32)$. In this way, Kogel's results based on econometric panel data techniques of 21 OECD countries for the period 1960 and 2000, respectively, showed between fertility and female participation in the labor force, a negative correlation was observed (33). These results were not consistent with ours. The reason may be that due to data constraints about women and men unemployment separately, we used total unemployment in the study according to statistical center of Iran data. Another reason might be the difference of our context comparing those countries, which are mostly developed. Considering our context and situation and importance of employment, especially for men, there are some important explanations about the relationship between unemployment and fertility. The first point turns to the importance of 
job security that is much more essential than job creation. If government generates some jobs, almost temporary or contractual cases, families postpone their childbearings and reduce them, because of the uncertainty of their future career. Hence, this type of employment would not aid much to enhance overall fertility. Another point is about the amount of advantages and facilities of a job. If household income is low compared with its expenditure, due to lack of sufficient financial ability or wage to cover the costs of childbirth, family could not raise fertility. Final note is associated to the provision of facilities for pregnant mothers and then facilities such as kindergartens for children of employees. If the system does not offer such facilities, a person with a job and even job security might still have lower fertility.

\section{Study Limitations}

Although, this study in terms of using rich data from several census as well as longitudinal data collected from various bodies might have important and useful points for policy-makers and officials but like any other study has limitations and due to limited available data, a group of variables such as culture and values were excluded. In addition, since the provincial data were collected over a long period, so for a number of provinces in the period in question, the data were not separated, so we combined data from these cases.

\section{Conclusions}

This study showed that divorce rate has an adverse effect on TFR. In addition, there was a significant direct relationship between marriage rate and TFR. Furthermore, urbanization rate and unemployment rate did not have significant relationships with TFR. Due to the less effect of some socio-economic factors on TFR, it could be concluded that other variables outside of the studied factors, such as cultural and value-related issues in addition to social economic factors, might play a role in this area and have more effect and prominent role on TFR decrease. Preparing the ground for sustainable employment and improving job security in the future, along with providing the facilities, such as insurance, housing for adults are suitable suggestion. In addition, providing the necessary skills in family for mate selection to have better durability as well as emphasizing communication, emotional, cultural skills after marriage as very important topics could be helpful in this area. Finally, emphasis on family roles in marriage procedures that would be much lower divorce. It should be noted that, despite the common perception that the socioeconomic factors in Islamic Republic of Iran are major causes of reduced fertility, the results of our study show that other factors, including cultural values and contexual values, might have greater effects. Thus it is recommended that more studies be conducted focused on the effects of such factors.

\section{Acknowledgments:}

This article was taken from a Ph.D. thesis in health policy. The authors sincerely express their thanks to all participants in the study and thank the anonymous referees of this Journal and recognize their help and guidance.

\section{Conflict of Interest:}

There is no conflict of interest to be declared.

\section{Authors' contributions:}

All authors contributed to this project and article equally. All authors read and approved the final manuscript.

\section{References:}

1) Organisation for Economic Co-operation and Development (OECD). Babies and Bosses: Reconciling Work and Family Life. Australia, Denmark and the Netherlands. OECD Report. 2002; 1: 1. doi: $10.1787 / 9789264104204$.

2) Ministry of Health, Treatment and Medical Education. Ten-year report of the Islamic Republic of Iran on the goals of the International Conference on Population and Development, Tehran, Iran, 2004.

3) Organization for Economic Co-operation and Development (OECD). Fertility rates (indicator), OECD Report, 2015. Available from: https://data.oecd.org/pop/fertility-rates.htm. doi: 10.1787/20747721.

4) United Nations. World Population Prospects: The 2006 Revision, UN Report, New York. Available from: http://www.un.org/esa/population/publications/wpp2006/wpp2006.htm. doi: 10.18356/02911.

5) Shapiro D, Kreider A, Varner C, Sinha M. Stalling of Fertility Transitions and Socioeconomic Change in the Developing World: Evidence from the Demographic and Health Surveys. Department of Economics Pennsylvania State University Park. 2011: 1-15.

6) Shapiro D, Gebreselassie T. Fertility Transition in Sub-Saharan Africa: Falling and Stalling, Afr. Popul Stud. 2008; 23(1): 3-23. doi: 10.11564/23-1-310. 
7) Statistical Center of Iran. Indicators of population in Iran, 2012. Available from: https://www.amar.org.ir/Default.aspx.

8) Demographic and Health Survey. Tehran: Ministry of Health and Medical Education, 2002.

9) Abbasi Shavazi MJ, McDonald P, Hosseini Chavoshi M. The fertility transition in Iran. Revolution and Reproduction. 2009; 75. ISBN: 978-90-481-3197-6.

10) Supreme Council of Cultural Revolution (SCCR). National programs to promote population growth and fertility rates. Tehran: Center for Women's Affairs and Family, 2013.

11) Erfani A. Fertility in Tehran city and Iran: rates, trends and differentials. Population studies journal. 2013; 1.

12) Adsera A. Changing fertility rates in developed markets. The impact of labour market institutions. J Popul Econ. 2004; 17: 17-43. doi: 10.1007/s00148-003-0166.

13) Mills M, Blossfeld HP, Klijzing E. Becoming an adult in uncertain times: A 14-country comparison of the losers of globalization. Globalization, uncertainty and youth in society. Routledge. 2005; 393-411. doi: $10.1177 / 0038038507084834$.

14) Caldwell, John C. Theory of Fertility Decline. Academic Press. 1982. doi: 10.2307/351322.

15) Blacker J, Opiyo C, Jasseh M, Sloggett a, Ssekamatte Ssebuliba J. Fertility in Kenya and Uganda: A Comparative Study of Trends and Determinants. Popul Stud. 2005; 59(3): 355-73. doi: $10.1080 / 00324720500281672$.

16) Kreyenfeld $M$. Uncertainties in female employment careers and the postponement of parenthood in Germany. EurSoc Rev. 2010; 26: 351-66. doi: 10.1093/esr/jcp026.

17) Shakoori R. Divorce and its developments in Iran: 1986-2006, a case study in Qom, master's thesis. University of AllamehTabatabai. 2011.

18) Notestein F. Economic problems of population change, in Proceedings of the International Conference of Agricultural Economists. Oxford University Press. 1953; 13-31. doi: 10.2307/40197878.

19) Abbasi Shavazi MJ, Asgari Nodoushan A. Family changes and reduced fertility in Iran, a case study in Yazd province. a social science. 2005; 25: 25-75.

20) Abdul Salam A. Nuptiality and fertility in Saudi Arabia: An appraisal of census data. Middle East Fertil Soc J. 2013; 18(13): 147-53. doi: 10.1016/j.mefs.2013.04.006.

21) Bongaarts J. The end of the fertility transition in the developing world, Working Paper, Population Council. Popul Dev Rev. 2002; 28(3): 419-43. doi: 10.1111/j.1728-4457.2002.00419.

22) Abbasi Shavazi MJ, Hosseini Chavoshi M. Fertility developments in Iran in the past four decades: using and evaluating their children fertility estimates using 1986-2011. the Institute for Statistics. 2013.

23) Hu J, Liu F, You J. Panel data partially linear model with fixed effects, spatial autoregressive error components and unspecified intertemporal correlation. J Multivar Ana. 2014; 130: 64-89. doi: 10.1016/j.jmva.2014.05.002.

24) Kazemipour Sh, Khoshnevis A. Meta-Analysis of studies on levels, trends and determinants of divorce in Iran and selected countries 1970-2011. Population Studies Journal. 2013; 33-59.

25) Lee YJ, BumPass L. Socio economic determinants of divorce/separation in South Korea: A focus on wife's current and desired employment characteristics. Development and Society. 2008; 37(2).

26) Razeghi Nasrabad HB. A survey on factors affecting fertility of married woman aged 35-44 in selected provinces. population Studies Journal. 2013; 109-28.

27) Abbasi Shavazi MJ. Recent changes and the future of fertility in Iran, paper presented at the Expert Group Meeting on Continuing Fertility Transition. Population Division of the United Nations. 2002; 13-8.

28) Ranjbar F, Shirzad M, Kamali K, Akhondi MM, Ghoodjani A, Behjati Ardakani Z, et al. Fertility behaviour of Iranian women: A community-based, cross-sectional study. Arch Iran Med. 2015; 18(1): 2-5. doi: 0151801/AIM.003. PMID: 25556378.

29) Addio D, Ercole M. Policies, institutions and fertility rates: A panel data analysis for OECD countries. OECD Econ Stud. 2005; 41. doi: 10.1787/16097491.

30) Gauthier AH, Hatzius J. Family benefits and fertility: An econometric analysis. Popul Stud. 1997; 51(3): 295-306. doi: 10.1080/0032472031000150066.

31) Billari F, Kohler HP. Patterns of low and lowest-low fertility in Europe. Popul Stud. 2004; 58(2): 161-76. doi: 10.1080/0032472042000213695.

32) Brewster KL, Rindfuss RR. Fertility and women's employment in industrialized nations. Annu Rev So. 2000; 26(1): 271-96. doi: 10.1146/annurev.soc.26.1.271.

33) Kogel T. Did the association between fertility and female employment within OECD countries really change its signs? J Popul Econ. 2004; 17(1): 45-65. doi: 10.1007/s00148-003-0180. 